\title{
ARTICLES
}

\section{Occupationally related illness: its compensation and its prevention}

\author{
Ian B Campbell*
}

In the major industrialised nations of the Northern Hemisphere, it is now being recognised that the problem of work-related illness is one of considerable dimensions. Despite the advantage New Zealand enjoys with its Accident Compensation legislation, in such matters, we lag behind the best of overseas practice. The article examines the part that recognition of such illnesses for compensation purposes plays in highlighting the need for preventive measures and suggests that, unless more effort is put into research into causation and allied problems, the work connection will not be established. Thus, not only will compensation not be paid but also, preventive measures will not be instituted.

\section{Introduction}

Since the end of World War 2, increasingly greater attention has been paid to the problem of occupational accidents and traumatic injury, but it is only more recently that the unknown but considerable toll of occupationally related illness has begun to attract the attention that it deserves. One of the difficulties faced by those anxious to see more action in this area is the fact that, whilst many illnesses can be occupationally related, they may also be contracted elsewhere than at work. Furthermore, there is ample evidence to suggest that the extent of the problem is considerably greater than generally appreciated and it is this unknown factor which is most confounding. To a considerable extent the recognition that a condition is work-related depends on the relevant compensation law and how it is administered. Here, the very slow liberalisation of the law in most, if not all, jurisdictions has been all too evident.

In his initial report to the Ontario Provincial Government on reshaping Workers' Compensation, Weiler (1980) states:

Industrial disease bids fair to be the major battleground of the next decade, exposing serious questions about the future viability of Workers' Compensation.

Apart from the advantage of its Accident Compensation scheme, New Zealand is no different. For here also, and for too long, too little attention has been paid to the problem of work-related illness, both with respect to its prevention and to its compensation. As in many other countries, there has never been an in-depth inquiry to identify the extent of the problem, the measure of which goes largely unappreciated by many bodies and individuals who should be to the forefront of preventive action or its advocacy.

Whilst the objective of this paper is to direct attention to the need for far more action aimed at the prevention of occupationally related illness, as suggested above, it is essential 
that there first be a review of compensation aspects. Attention is therefore first directed to the relevant provision of the Accident Compensation Act 1982 (which has its counterpart in the corresponding legislation of many countries) and the manner in which that provision has been interpreted by the Accident Compensation Corporation (formerly Commission) (ACC) and the Accident Compensation Appeal Authority.

\section{The compensation provisions: their interpretation and operation}

Section 28 of the Accident Compensation Act 1982, with which we are concerned, has its origin in the previous workers' compensation legislation where, over many years, those and similar provisions have been the subject of numerous decisions of various appellate courts in many jurisdictions. The section reads in part:

\footnotetext{
If a person's total or partial incapacity or death results from any disease, and the disease is or was due to the nature of any employment in which the person was employed as an earner during a period that ended on or after the 1st day of April 1974 ...
}

The key words are "due to the nature of any employment", but at the outset it should be emphasised that the problem does not begin and end as a matter of interpretation of the statute. As we shall see, it is much more complex; for it also involves the factual position as to whether or not there was a casual relationship between the illness causing incapacity or death and the employment.

In many countries, such legislation sets out a number of specified diseases and their respective industries or occupations and which provisions create a presumption that there is a nexus between the industry or occupation and the disease. In the main such presumptions do not add very much to the interpretation of the statute for to a considerable extent they merely state what, in the light of today's knowledge, should be largely obvious: for example:

Poisoning by lead or a compound of lead - Any occupation involving: The use or handling of, or exposure to the fumes, dust or vapour of lead or a compound of lead or a substance containing iead. (Social Security Regulation, 1980).

A difficulty with such schedules is that, unless there is an omnibus provision, cases will arise where the effect of a substance not listed will not attract compensation until it, in turn, is added to the list; often a long drawn out process. In New Zealand, the Royal Commission of Inquiry into Compensation for Personal Injury (The Woodhouse Commission) made a novel suggestion that consideration be given to specifying certain categories as set out in the International Classification of Diseases (compensation for personal injury in New Zealand; Report of the Royal Commission of Inquiry, 1967) but that suggestion was not followed. In many countries the position has been further confused by the recognition under workers' compensation law that certain diseases may be considered to be contracted as a "result of personal injury by accident"; a relic of the days before there was any provision relating to occupational illness. (Brintons Ltd v. Turvey, 1950).

\section{Case law}

A number of important cases have been decided in New Zealand since the Accident Compensation Act 1972 came into force in 1974. In the main, those cases, which concern occupational illness depend upon the interpretation of the words "due to the nature of any employment", but there have been others which has been decided on the facts - the possible occupational causation rather than a matter of law.

In the case of an appeal by Dryden, the Appeal Authority traced the history of the relevant words in the section from the time of the 1947 amendment to the Workers' 
Compensation Act 1922, through to the 1972 predecessor to the present Act. Two decisions of the High Court of Australia were referred to (The Commonwealth v. Thompson, 1959-60; The Commonwealth v. Bourne, 1959-60) but the importance of the slight difference in the wording of the Australian statute was commented upon. Whereas the New Zealand Act refers to "any employment" the Australian Act in question refers to "the employement". The judgement goes on:

The liberal intention of Parliament must be given effect to in construing s. 19 of the Workers' Compensation Act, and now s. 67 of the Accident Compensation Act. In addition, the phrase any employment must be given effect to. "The word any is a word of very wide meaning and prima facie the use of it excludes limitations." (Re Dryden Decision No. 79).

Apart from the problem of determining causal factors, one could well question whether in the light of today's greater knowledge of and concern with occupationally related illness, the present provisions adequately meet the undoubted needs. In the report of the Woodhouse Commission it was clear that their conviction was that a strictly legalistic approach will not do justice to the situation, as their references to the proposed administrative body (now ACC) confirms:

Independence would be necessary to enable this body to work with detachment in the new field; and given a constitution wide enough to ensure that its decisions would never become illiberal and would always be made upon the real merits and justice of the case ... (Compensation for personal injury, 1967 p. 86).

and later:

There should be discretion to deal with any unusual circumstances and every decision should be based on the real merits and justice of the case. (Compensation for personal injury, 1967 p. 127).

That the current position is not as envisaged by the Woodhouse Commission is evident from many of the issues raised before the Appeal Authority and here the words of Lord Diplock concerning the British Social Security legislation are of more than passing interest:

To find the meaning of particular provisions in social legislation of this character calls, in the first instance, for a purposive approach to the Act as a whole to ascertain the social ends it was intended to achieve and the practical means by which it was expected to achieve them. Meticulous linguistic analysis of words and phrases used in different contexts in particular sections of the Act should be subordinate to this purposive approach. (Jones v. The Secretary for Social Services, 1972).

The present position in New Zealand is scarcely surprising since so many of those responsible for making the early decisions within ACC and elsewhere were previously involved with the administration of the Workers' Compensation Act in one way or another. They were well acquainted with the standard of proof then required as to causation and other matters. Furthermore, they were still being guided by a statute which perpetuated identical language in many vital sections and nowhere in the Act is there any reflection of the Royal Commission's basic ideals. In effect, the restrictive standard of proof applicable under Workers' Compensation seems largely still to apply.

\section{Commentaries on the present position}

After referring to the Woodhouse Commission's views on the need to base decisions on the real merits and justice of the case, Palmer (1979) comments:

Such liberality found no favour with the legislators who spelt out a system of entitlement 
where the applicant must prove his case under detailed sections drawing very fine lines. Both the Commission and the Appeal Authority take the view that the applicant must prove his claim, a posture that brings back some unfortunate memories of the common law on some occasions. The Commissioners have felt the need for greater flexibility, and this is reflected in the amendments they have sponsored.. (P. 400).

and again:

The administration of the Act in New Zealand has not matched the vision of the original blue print. (P. 404). illness.

Nowhere would these factors make for more difficulty than in the field of occupational

Ison's (1980) comments on the New Zealand position are also of considerable interest and are in line with the views of Lord Diplock and Palmer above.

In social insurance, as in other areas of justice and public administration, it is difficult to formulate clear statements of burdens and standards of proof that can and will be applied consistently. In an apparent attempt to avoid some of the complexities found in legal literature, the ACC has prescribed as its evidentiary test: "from the information and evidence available, does the claims officer agree and believe that the claimant is entitled to rights under the Act?"' (p. 94).

The former Appeal Authority has published 2 books on Accident Compensation and in the second one, after referring to the fact that with Accident Compensation and in the latter one, after referring to the fact that the "onus of proof" rules do not apply and that the adversary system is not used in the administrative process, stated:

... his claim may be examined by the Corporation's officers in an inquisitorial and investigatory way whereby they assist in collecting the relevant material. (Blair, 1983, p. 180)

and later he quoted from Dixon J. a passage which has since been approved by Davidson C.J.:

The truth is that when the law requires the proof of any fact, the tribunal must feel an actual persuasion of its occurrence or its existance before it can be found. It cannot be found as a result of a mere mechanical comparison of probabilities independently of any belief in its reality. (Blair, 1983, p. 178).

The instructions in the ACC's claims manual state:

A disease is due to the nature of a person's employment where it can be shown either:

that there was a causal connection between the particular work and the disease;

that the general class of work in which the person is engaged has by its nature a recognised tendency to cause the disease and, accordingly, people in that class of work are exposed to a special risk of contracting the disease.

It is therefore not surprising that Ison (1980) goes on to point out the difficulties of such an approach, suggesting that whilst it is reasonable that the claimant should provide all the evidence at his disposal:

But in a social insurance system, it is also important that a claims officer should accept the burden of obtaining all the evidence that can be obtained more conveniently or more efficiently by the tribunal than by the claimant. The ACC is not a common law court and a claimant should not have to "prove his case" (p. 94)

Then after commenting on the desirability of adopting the common law standard of proof based on the balance of probabilities, Ison (1980) suggests another alternative: 
that where the facts are doubtful (including questions of etiology) the claims officer should seek to determine the best available hypothesis. Recognising the problem of occupational illness, he goes on:

The matter can be critical in a claim for occupational disease where the etiology of a
disability may be unknown. The medical opinion may well be that the disease could be
due to the nature of the claimant's employment, or it could have been caused by circum-
stances independent of the employment. Rather than weighing up the probabilities from
the circumstantial evidence, the practice in such cases appears to be to assume that the
absence of positive data requires a negative assumption. Among other objections, that
approach penalises claimants for limitations of medical science. There is surely a res-
ponsibility on the tribunal to decide what is the best available hypothesis. (p. 95).

The problem is therefore not only a question of the standard of proof but also the extent to which it is desirable that ACC or any like body should merely stand back, as it were, and let the claimant provide his evidence, or whether it should actively assist the claimant in this task. Ison could well have suggested that ACC follow the Canadian practice of appointing claimant's advisers; emphasising the necessity for such persons to be, and be seen to be independent.

The most recent comment from an overseas study group is contained in a report to the Quebec Government following a visit to New Zealand by M. Robert Sauve, the PresidentDirecteur General of the Commissior de la sante et de la securite du travail du Quebec in late 1981. After referring to the restrictive interpretation of the law and the strongly legalistic approach, the report (translated from the original French) goes on:

It equally appears to us that the Corporation expected from the claimant the proof necessary to uphold the claim. We did not encounter in the procedures examined or during the conversations a desire on the part of the organisation to simplify the task of the claimant whether by limiting the elements of proof required for the rapid processing of the claim or by facilitating the means of proof by legal rules favourable to the claimant. (Mission sur les lesions professionelles, 1981, p. 51).

Shortly after that Quebec visit, in its annual report for the year ended 31 March 1982, ACC stated:

The change in policy is a departure from what used to be called an "insurance attitude", a somewhat grudging attitude towards claims. The corporation's board, shortly after its appointment, made it known that if a person suffered an accident, assistance by the corporation was to be regarded as an entitlement and his right. It is confirmed that the corporation would willingly assist an accident victim as far as it could in securing his or her legitimate and proper benefits under the Act, whether financial or by the provision of rehabilitation aids or services. (Accident Compensation Corporation, 1982).

Welcome as that statement may be, that change in attitude is not really the answer to the points raised by both Palmer (1979) and Ison (1980). What is needed is a provision similar to one embodied in section 99 of the British Columbia Workers' Compensation Act 1979 which reads:

The board is not bound to follow legal precedent. Its decision shall be given according to the merits and justice of the case and, where there is doubt on an issue and the disputed possibilities are evenly balanced, the issue shall be resolved in accordance with that possibility which is favourable to the worker.

The Ontario Workers' Compensation Amendment Bill of 1984 proposed a similar provision referring to the "real merits and justice of the case", calling for such an issue to "be resolved in favour of the claimant".

Weiler (1983), in his second report to the Ontario Government points out the differing demands on the system of compensation and prevention. He sees the only solution to the illness compensation problem in these terms: 
... the conclusion emerges that we should have a general scheme for compensating the victims of all disabling diseases... (Weiler, 1983, p. 131).

Whilst, in principle, it would only be equitable if all persons suffering an illness were compensated on the same basis irrespective of cause, that course, if adopted, would mean that there could be even less liklihood of establishing the work connection with the illness, if any, than at present. Weiler goes on to recommend that:

A somewhat greater share of the resources of the compensation program should be devoted to study of the causes and potential control of industrial disease. (Weiler, 1983, p. 139).

\title{
Issues raised
}

The task of delivering real justice reflecting the true merits of the claim is more difficult in the field of occupational illness than with traumatic injury. It raises points that many eminent persons have been wrestling with in a number of countries. In the early days of workers' compensation, there was no provision for the compensation for occupational illness and as a consequence no doubt, some illnesses were held to be "personal injury by accident". When coverage was ultimately provided, it was hedged around with restrictions to ensure firstly, that the illness was indeed occupationally related and secondly, that the burden of the compensation liability fell upon the employer (or his insurer) where the exposure occurred. As a consequence of these restrictions many deserving claimants missed out, for the difficulties faced by a worker in providing the necessary proof were daunting. Not only did he have to prove that he had a particular disease but that it was due to the nature of the employment and to specify that employment. Difficulties of proof arose from the fact that some illnesses could be both work-related and non-work-related. This resulted in the schedule of prescribed diseases to be adopted.

Recently in Britain the Pearson Royal Commission in recognising this:

\begin{abstract}
... recommended that in addition to compensating the occupational diseases listed in the schedule of prescribed diseases, benefit should become payable where the claimant could prove that his disease was caused by his occupation and that it was a particular risk of his occupation. (Report of the Royal Commission on civil liberties and compensation for personal injury, 1978).
\end{abstract}

As a result of that recommendation an independent body, the Industrial Injuries Ad. visory Council was given the task of reviewing that recommendation. Wilson (1982) in commenting on that recommendation refers to the restrictive effect of the words "a particular risk of the occupation":

The reason behind the test was to limit the claims, so that the system would not be flooded by claims, as was feared. (Wilson, 1982, p. 142).

Perhaps not surprisingly, the Advisory Council was of a similar view namely that it was necessary to restrict access to the compensation process so that any authority charged with the task of administration would not be overwhelmed with a large workload. (Wilson, 1982 , p. 143). Such a stance is not uncommon as bureaucratic authorities are often wont to be more attentive to administrative convenience than to dispensing natural justice. A recent report $(\mathrm{RKL}, 1984)$ indicates that the Council recommendation was not accepted by the British Government.

However, Britain, in passing the Social Security and Housing Benefit Act 1982, appears to have walked away from the problem. That Act abolishes the Injury Benefit for workrelated injuries and specified diseases. As a consequence, employers are now liable to meet the cost of sick pay for the first 8 weeks of incapacity, which payments are recoverable by a means of a deduction from monthly insurance contributions to Social Security. There- 
after an injured worker receives the standard sickness benefit.

What then are the major problems? Unfortunately, as has already been stated, there are many conditions that may undoubtedly arise out of the employment but which may also occur otherwise than at the workplace, being one of the common illnesses to which all humans are prey. In some cases, courts have recognised that the contraction of such an illness may be clearly work-related. For example, where a miner, perspiring as a result of his work, had to wait an hour and a half in a draft of cold air, contracted a chill and subsequently died of pneumonia (Brown v. John Watson Ltd, 1915).

Many cases are far from being clear-cut and it is well known that many illnesses which do not manifest themselves until many years after the exposure to the offending substance. This long period of latency often presents a substantial problem of proof. Furthermore, a worker may, in many instances, be unaware that he has been so exposed or of any possible consequences, whilst at times an employer may have been equally unaware of an individual's actual or possible potentially hazardous exposure. Sometimes this will be because the hazardous nature of the substance has not been identified or accepted as such. On the other hand there have been cases recorded of employers deliberately withholding such information. The vast number of new chemicals and substances coming into common usage each year are also a cause for concern, for whilst the great majority may well be benign it is not too much to state that some will probably be toxic or present other undesirable attributes, attributes that may not become apparent for many years after their introduction.

\section{Possible solutions}

What then may ensure that greater justice is done and even more important, that the use of a particular substance which possesses a potential for harm is either, replaced by a safer alternative, better controlled, or restricted in its manufacture, transport and use? Several strategies have been suggested. The commonly accepted practice of scheduling illnesses together with the substance or process which may be a causative factor, does not meet the problem of those illnesses which may be found in the community at large as well as being clearly work-related in some circumstances. Nowhere is this aspect more confounding than with many cancers. There are some substances in use in industry which cause or are suspected of causing lung cancer but so does smoking. The usual measures adopted to establish or disprove a substance to be carcinogenic may involve animal experiments, or an epidemiological approach, identifying a higher incidence of a particular condition in a defined occupational group than would be expected in a similarly matched group from the general population. Often there would be limitations to the extent to which any court or administrative authority would accept such evidence as the basis for payment of compensation.

Traditionally, the person affected has been charged with providing the proof and one could well ask what would be the position where the epidemiological evidence was that the chance of a particular group of workers incurring a particular cancer was shown to be 3 times that in the general population. Clearly it could be said that of those workers exposed to the carcinogen in question, some could be expected to contract that condition even if they had not been exposed to the substance. If, in a group of workers, say 15 contacted the particular cancer, whereas in the matched group in the population at large only about 4 or 5 could be expected to succumb, what should be the outcome? Would there be any more justification for declining compensation in all cases: this on the grounds that of the 15 some would have been victims in any case and thus only about 10 could be said to suffer a work-related illness? In other words, it is more acceptable to deny justice to the unidentified 10 or so rather than pay compensation to the 15 of whom about 5 may possibly not have been entitled on the basis of the epidemiological evidence? Another way of putting it is; who should suffer the injustice - the unfortunate workers or the employer (or as in New Zealand, the authority providing the compensation)? A situation, 
which calls to mind Blackstone's (1769) pertinent comment: "It is better that 10 guilty persons escape than one innocent suffer."

An examination of the history of workers' compensation in many countries will reveal that as far as compensation for accidental injury is concerned, there has been a gradual relaxation over the years and a change from a policy of ensuring that no undeserving case is compensated, toward one of ensuring that all deserving cases are accepted. However, evidence of such a shift in the manner in which occupational illness is dealt with is largely conspicuous by its absence.

Undoubtably the solution is far from simple and a note in the Harvard Law Review (1980, p. 937) concludes:

\begin{abstract}
This note has examined the treatment of occupational disease victims under existing compensation systems, in particular workers' compensation and product liability actions. Shaped in response to the problem of industrial accidents, these systems have poorly served those with work-related illnesses. Reforms should be fashioned to ease the burdens of occupational illnesses on their victims. The intricacies of a new compensation system might well include the use of existing agencies to process the claims of workers with diseases, the creation of rebuttable presumptions of work-disease relationships to facilitate individual recoveries, and the employer liability for prospective claims with goverment assumption of retroactive payments. Such a compensation system will inherently be flawed because of the complexity of the disease phenomenon. However, this fact should not lead to complacency about the failures of existing compensation mechanisms.
\end{abstract}

In the United States, the reference to government assumption of retroactive claims relates to the Black Lung Benefits Reform Act of 1977, which covers compensation for miner's pneumoconiosis. But in New Zealand, ACC is ideally placed to take up the challenge. Having the sole responsibility for compensation, it is not inhibited in the way that are insurance institutions in other jurisdictions where rights and responsibilities of individual employers and their insurers have to be considered. In the United States this problem gave rise to the Black Lung Act. Even now, in New Zealand however, with some conditions such as those created by exposure to asbestos, such as asbestosis and mesothelioma, the position is still far from satisfactory. Though asbestos-related and some other diseases usually take many years to manifest themselves, a worker who, since 1 April 1974 , has not been exposed to any harmful substance, the effect of which develops over many years, will have no claim against ACC or his previous employer where the exposure occurred, or that employer's insurer under the previous workers' compensation legislation. That Act did not recognise a period of latency longer than 2 years except for, since 1962 , 20 years for radiation illness and since 1967, 10 years in respect of hydatids.

Another aspect is the undeniable fact that a person's need for compensation arises not as a result of whether or not the illness was work-related but from the nature and extent of the illness. The legal position merely determines the extent to which the loss falls on the individual or on the community through Accident Compensation or other income substitution payment system. Only preventive measures will eliminate or reduce the true cost, both to the individual concerned and the community which in the ultimate provides all forms of income replacement.

\title{
Financial aspects
}

In workers' compensation jurisdictions the question of the basis upon which insurance premiums have been calculated and paid, along with the problem of unforeseen types of claims has given rise to considerable debate. The fact that claims can arise in respect of periods of exposure for which no premium was charged for that type of claim, has had a constraining influence. Witness the furore raised in the United States when compensation claims for noise-induced hearing loss first had to be met. The resistance to the extension of the employer's liability for compensation and often a concurrent objection to the widening of any safety code has, at times, led organised labour to perceive what they 
regard as an unhealthy symbiosis between the employers and the regulating authorities. In this, the unions are hampered by the fact that any data or other information is often exclusively in the hands of the employers. That this concern might be justified can be illustrated by the objections that were raised to the 1976 proposal by the Occupational Safety and Health Administration (OSHA) in the United States to establish a new standard for polyvinyl chloride (PVC). At the OSHA hearings, the plastics industry presented studies predicting a loss of \$69-90 billion and about 2 million jobs. Actually, the real cost of compliance was about $\$ 325$ million in capital and a loss of 290 jobs through the closing down of two plants. (Epstein, 1979, p. 312).

Among the aspects of occupational disease compensation which differ from personal injury compensation is that of incentives. The call for experience rating for employers has been partly heeded by ACC with the payment of rebates to employers with significantly better than average accident records even though it has refrained from imposing the more justifiable penalties in appropriate cases which it is empowered to do. With occupational illness, apart from the problem of latency, it may often be impossible to identify the actual employer in whose employment the exposure occurred or it may be the cumulative result of exposure in the service of serveral employers. It would be possible for an employer to receive a rebate from ACC for an apparently good record, yet for that employer to be exposing his employees to a highly toxic substance, the result of which may not be evident for many years. Ison's commentary on the New Zealand scheme remarks:

Occupational diseases are under-reported compared with injuries and the real incidence of occupational disease will never be discovered from claim statistics. The use of claims data may therefore result in a misallocation of resources emphasising the prevention of occupational disease. (Ison, 1980, p. 175).

Thus experience rating is quite inappropriate insofar as the prevention of work-related illnesses is concerned and can play no part.

\section{The incidence of occupationally related illness}

In the more advanced industrial countries, there is a growing concern at the effect of the working environment on the health of those employed and, in some cases, on that of the public at large. In no aspect has this concern been more widely expressed recently than at the effect of exposure to asbestos. There are many other substances in regular use in industry today that are similarly dangerous to health and many more substances are suspected of being harmful. In a great number of cases proof is either lacking or not sufficient to draw a firm conclusion. Even where a worker may be suffering from a condition due to exposure to some known harmful substance, the origin of that condition may go unrecognised for a variety of reasons. As has already been mentioned, many work-related conditions present the same or similar symptoms found in patients with no exposure. Then there are the complications of latency and the fact that any possible work connection many years back in the past may be overlooked by the patient.

Though the dangers of asbestos have been known for many years and more particularly since the work of Selikoff and his colleagues at the Mount Sinai School of Medicine (Selikoff, Churg and Hammond, 1965) in the early 1960s, it was not until 1979 that the Asbestos Regulations were gazetted in New Zealand, some 46 years after the Asbestos Industry Regulations came into force in Britain. Though in this and other ways we have tended to lag behind the action being taken in many other countries in matters of occupational health, New Zealand is by no means unique for elsewhere health aspects still tend to play a minor role as compared with safety issues though much is now changing. The reason for this is not difficult to discover, for, in short, the true extent of the problem is unknown. For example, in the United States deaths annually from occupational illnesses have been estimated from as low as 1000 to as high as 100000 . There, an Interagency Taskforce on Workplace Safety and Health (1977) in referring to the increasing concern 
over health effects of workplace exposure to toxic substances and the estimates that had been made of the number of work-related cancer deaths stated:

Beyond these controversial and gloomy estimates it is generally conceded that the nature and extent of US occupational diseases is largely unkown. The often-quoted DHEW ${ }^{1}$ past estimate of 390,000 new cases of work-related disease and 100,000 deaths per year is felt by others to be very approximate. However, no better estimates are available. Partly because most occupational disease is not diagnosed or recorded. More research is needed to identify the effects of harmful substances or combinations of substances whose interactions are suspected or unknown. (Interagency Taskforce on Workplace Safety and Health, 1977, p. 17).

From Canada Ison (1978, p. 2) states:

It is possible that the actual incidence of disablement from industrial disease could be several times that which would be indicated by the statistics of compensation claims. To begin with, there are several difficulties in obtaining medical opinion on diagnosis and etiology for deciding whether a disease should be classified as one resulting from employment. Occupational medicine has not actually been a signficant part of the training of medical practitioners. However, many diseases and their etiology are not obvious from signs and symptoms alone. A reliable opinion on diagnosis or on etiology often depends upon a clinical finding being compared with occupational history. It is still fairly common to find, however, that a complete occupational history has not been taken by an attending physician, even in cases in which it might establish an industrial basis for the disease.

Clearly the import of these statements also applies to New Zealand even if the incidence and nature of such illnesses may differ.

Again Ison's commentary on the New Zealand scene is of particular relevance when he states:

In spite of the rising incidence of respiratory and other cancers in New Zealand industry, and in spite of the carcinogens used in New Zealand industry, there is still no signficant flow of claims for cancer resulting from employment. (Ison, 1980, p. 166).

Ison goes on to mention that, whilst Cancer Registration Form 391 asks for smoking habits prior to diagnosis and occupation, it does not ask for occupational history. He also notes that though ACC rehabilitation officers systematically visit orthopaedic wards in general hospitals, there is no such visiting of medical wards to take the occupational history in any case where a disease may have an occupational origin. And later:

The volume of disabilittes from occupational disease is grossly under-recorded. It could even exceed the volume of disabilities from occupational injuries. For many of the most serious occupational diseases the latency period is long, sometimes 20 years or more. For this reason, and for other reasons relating to the recognition of occupational disease, the costs of occupational disease are usually externalised to a much greater extent than the costs of occupational injuries. Because of the time factor and the externalisation of costs, any health and safety program that appeals to the profit motive creates a risk of diverting attention away from health measures. (Ison, 1980, p. 166).

Whilst, to some, the failure to diagnose a condition as occupationally related may result in 1 less claimant being entitled to Accident Compensation, the problem runs deeper. So long as the link between the work and the illness remains unrecognised, then the chance to institute preventive measures will be lost. There are many other aspects too, for not only may the health of workers be affected by workplace activity but on occasions the community as well, by emissions from the workplace itself or its products and even the worker's family by harmful substances brought home in clothing. 
Almost unrecognised is the problem of stress arising out of the work environment and the activity therein. Serious health problems may ensue not only affecting the worker but the family as well. Thus it is increasingly appreciated that it is not only the physical, chemical and biological aspects of the workplace with which we are concerned but also the psycho-social.

\section{Future action}

From the facts and views thus far outlined, it is clear that progress towards healthier and safer workplaces will only be accelerated when there is a better appreciation of the totality of the problem by all involved. At the same time, the medical profession, more particularly general practitioners, nurses and other primary health-care personnel, are encouraged to consider the work history of their patients. This could possibly help establish whether the working environment, even many years in the past, may have had some precipitatory or other influence on the present condition of their patient. Increasingly it has become recognised that many health problems will only be identified by the application of epidemiological principles and methods, but for that to be successful, occupational illness must first be recognised as such and then the need for the recording of sound basic data has to be appreciated.

The right of individuals to know just what hazards may have a bearing on their health and safety and to which they may be or have been exposed, is a lively issue in many countries. Such information may extend well beyond that concerning the hazardous substances or processes; covering for example, details about a worker's individual exposure or even suspected possible exposure, medical records, and other relevant information. The key to the problem is the maintenance of adequate records and therefore, recent developments overseas are of special interests. The New Jersey Worker and Community Right to Know Act, P.L. 1983, Chapter 315, requires that employees and the public have access to: a list of hazardous substances used in each works, emission data on selected substances, fact sheets on these substances detailing health effects, symptoms, safe handling and first aid procedures. At the same time in Britain the Health and Safety Executive have circulated for comment a Code of Practice for the Control of Substances Hazardous to Health. Among the requirements in the proposed code are: the monitoring of the exposure to hazardous substances and the retaining of these records for 30 years, health surveillance records to be kept for 50 years, employers to investigate the risks associated with any substance, and be required to tell any employees of the risks that they run etc. Employees would have the right of access to their records. Such provisions are compelling evidence of the seriousness with which the hazardous substance problem is regarded overseas and is a clear indication of the action which we should follow in New Zealand.

The problem must be tackled on many fronts, bearing in mind the problem of latency of the effect of many hazardous substances and other unknown factors. However, unless medical practitioners are more aware of the possible connection between many conditions and work exposures, it is unlikely that they will ask the right questions thus diminishing the chances of collecting the necessary vital data. The notion of body counts to establish a nexus may be abhorent to many but in some cases it remains the only avenue open. The problem is so immense and the opportunity for research in New Zealand so limited, an extensive monitoring of current overseas research is crucial.

In the workplace there is a need for a great deal more knowledge of the hazards that are daily being faced or are likely to be faced if the correct procedures are not followed. In the larger industrial nations of the northern hemisphere, this has aroused not only a lot of interest but also positive action especially on the part of organised labour. There the right of the workforce to be informed of any hazards which they face has been exhaustively pursued, sometimes with considerable difficulty, and thus there is every reason for the introduction in New Zealand of a mandatory provision to cover this vital requirement. The implementation of the provisions of the Factories and Commercial Premises Act 1981 
with respect to joint management-labour health and safety committees and the appointment of workers' health and safety representatives would be of considerable assistance, given adequate training. In New Zealand the Accident Compensation Scheme removes any possible excuse for reticence or lack of action in such matters, which has often been a problem in many other jurisdictions.

The monitoring of the work environment is often the first essential but in New Zealand we have a serious lack of qualified personnel, let alone persons trained even in the elementary principles of the task. Another feature of some countries is the amount of training given to the workforce in the form of trade union education. So much so that in Britain and Ontario, Canada, for example, it has been stated that workers are becoming better informed on health and safety matters than their supervisors and middle management. Here in New Zealand, the Federation of Labour, which is well aware of the need to carry out extensive education among the membership of the unions, already has under way a project on trade union activity in occupational health and safety, and which includes the investigation of education for trade unionists as one of its important aspects. This is being undertaken with the assistance of a grant from ACC. Only lack of finance has prevented earlier action but even that, the Federation has been endeavouring to raise for some years. Recently the New Zealand Engineers' Union embarked upon a substantial education programme and already in excess of 200 delegates have been put through a course of training in occupational health and safety.

Recognising the difficulty of providing the necessary education for general practitioners, Easson (1981) in a report to the Prince Edward Island Government suggested an alternative approach, namely to get the patients to educate their physicians. He states:

\begin{abstract}
The idea is that it is much easier to inform a fisherman about the illnesses of his calling than it is to provide physicians with as detailed information about occupational illnesses of not only fishermen, but farmers, meat packers etc. There are a variety of routes whereby relevant information could be channeled to workers in various occupations, such as government departments, non-governmental federations, labour-management committees etc. (Easson, 1981, p. 25).
\end{abstract}

The major task that still faces New Zealand is to raise the level of awareness of the problems of occupational health and there is much that can be done. In this we have much in common with other countries even if they may be a little ahead of us. In Britain, for example, in 1982, the Employment Committee of the House of Commons heard submissions on health and safety problems in industry in recognition of the 10th anniversary of the tabling of the now famous Robens Report (Safety and health at work: Report of the Committee, 1972) and in that Committee's report the following appears:

\begin{abstract}
Within the United Kingdom the Health and Safety Commission drew a distinction between their work in the two fields of accidents and occupational disease. Although accidents are coming under control, the problems of occupational diseases are much more difficult to deal with. They consider that this should be a priority in the health and safety field, and they see a need for more professional people such as toxicologists, and epidemiologists. Not enough appears to be known about the hazards of occupational diseases however, and the Committee consider that more research and publicity is necessary, so that the Commission's efforts in this field should be directed to the best advantage. (Sixth Report from the Employment Committee Session, 1981-82, p. viii).
\end{abstract}

This comment, it is suggested, is even more relevant to New Zealand. Inevitably the question will arise as to what is the cost of such measures and though that amount would be difficult to quantify, it may well be that the cost of inactivity is much higher in material terms, to say nothing of human values. The challenge to reduce that cost and also give effect to the real merits of their case and the justice that industry's victims deserve. Small wonder, therefore, that Samuels (1982), when considering the plight of those employees at high risk in the chemical industry, puts these views on behalf of organised labour: 
of the worker and his or her family to manage legal, financial, and psychological problems of dying, but also those of lifetime surveillance, intervention and treatment. Developing such community-based programs focused on the special problems of past and present exposed workers and their families has, therefore, become a high priority of the American labour movement. (Samuels, 1982, p. 125).

In no aspect of this whole problem is the need for positive action more urgently required than in that of the use of carcinogens, not omiting the task of establishing more positively the properties of those many substances which may have an as yet unknown potential for harm. As a guide we could well heed the remarks of Gerwith (1980):

So far as the moral responsibility of agents is concerned, the Right to the Non-Infliction of Cancer is an absolute human right and it requires the most determined efforts both to ascertain when such infliction is likely to occur and to take all possible steps to prevent it, and thereby to make the respondents fulfil their correlative duties. (P. 125).

Though work-induced cancers are among the most serious types of work-related illness, nevertheless with many other conditions the difference is only one of degree and in all situations there is an undoubted duty to do a great deal more than is being done at present.

An immediate objective should be a consideration of the provisions of Convention 155 and Recommendation 164 agreed by the General Conference of the International Labour Organisation in 1981, with a view to implementing the changes necessary so that the convention could be ratified. The procedure recommended in both the convention and the Recommendation could be regarded as a blueprint for the action needed to make an initial attack on the problems outlined in this paper. In addition, there are many research papers which have been published recently in Britain, Canada and the United States which should be studied with a view to establishing the extent and depth of the present and potential problems in the New Zealand workplace. Such an inquiry would need an adequate back-up of competent researchers and have comprehensive terms of reference. Preventive aspects should at all times be paramount over legal matters, for the law should be regarded as the servant not the master, as it so often seems to be.

\section{References}

Accident Compensation Corporation (1982) Report of the Accident Compensation Corporation for the year ended 31 March 1982, Wellington, Government Printer.

Asbestos Industry Regulations S.R. 70 1931/1140, London, HMSO.

Blackstone, Sir W (1769) Commentaries on the laws of England : Book 4 Oxford, Clarendon Press (reprinted London, Dawsons, 1964)

Blair, A P (1983) Accident compensation in New Zealand (2nd edition) Wellington, Butterworths.

Compensation for personal injury in New Zealand, report of the Royal Commission of Inquiry (1967) Wellington, Government Printer.

Easson, I (1981) A report commissioned by the Prince Edward Island ministerial committee on occupational health and safety. Hamilton, Ontario, Canadian Centre of Occupational Health and Safety.

Epstein, S S (1979) Constraints in decision making Annals of the New York Academy of Sciences 329:309-317.

Gerwith, A (1980) Human rights and the prevantion of cancer American philosophical quarterly 17:118-125.

Harvard Law Review (1980) 93:916-937, Notes: compensating victims of occupational disease. 
Interagency task force on workplace safety (1977) Making prevention pay: final report of the Interagency task force on workplace safety. Rosslynn Va.

Ison, T G (1978) The dimensions of industrial disease Research and Current Series No. 35 Kingston, Queen's University.

Ison, T G (1980) Accident compensation: a commentary on the New Zealand Scheme London, Groom Helm

Mission sur les lesions professionelles (1981) Montreal, Csst.

Palmer, G W R (1979) Compensation for personal incapacity Wellington, Oxford University Press.

Report of the Royal Commission on civil liberty and compensation for personal iniury (1978) Cmnd 7054 London, HMSO.

Re Dryden Decision No. 79 (1977) NZAR

R K L (1984) Social security: benefit for industrial disease Industrial law journal 13: 128-130.

Safety and health at work: report of the committee (1972) Cmnd 5034 London, HMSO.

Samuels, S W (1982) The management of populations at high risk in the chemical industry Annuls of the New York Academy of Sciences 381:117-125.

Sixth report from the Employment Committee session 1981-82 London, HMSO.

Selikoff, I.J.; Churg, J and Hammond, E C (1965) The occurrence of asbestosis among insulation workers in the United States Annals of the New York Academy of Sciences 132:139-155.

The Social Security (Industrial Injuries) (Prescribed Diseases) Regulations 1980 S I No. 377 Pt 1 , London, HMSO.

Weiler, P C (1980) Reshaping workers' compensation for Ontario: a report submitted to the Minister of Labour.

Weiler, P C (1983) Protecting the worker from disability: challenges for the eighties Toronto, Ontario Government Bookstore.

Wilson, S R (1982) Occupational diseases - the problem of a comprehensive system of coverage Industrial law journal 11:141-166.

\section{List of cases}

Brintons Ltd v. Turvey (1905) A C 230.

Brown v. John Watson Ltd (1915) A C 1.

Jones v. The Secretary for Social Services (1972) A C 145, 181.

The Commonwealth v. Thompson (1959-1960) C L R 48

The Commonwealth v. Bourne (1959-1960) C L R 52. 